\title{
Urban Governance and Poverty Reduction in Uganda: Lessons from Foreign Aid Regime of Local Government Development Program
}

\author{
Shuaib Lwasa \\ Department of Geography, Geo-Informatics and Climatic Sciences, School of Forestry, Environmental and \\ Geographical Sciences, College of Agricultural and Environmental Sciences, Makerere University, Kampala, \\ Uganda \\ Email: shuaiblwasa@gmail.com, Iwasa s@caes.mak.ac.ug
}

Received 15 October 2014; accepted 30 December 2014; published 24 March 2015

Copyright (C) 2015 by author and Scientific Research Publishing Inc.

This work is licensed under the Creative Commons Attribution International License (CC BY). http://creativecommons.org/licenses/by/4.0/

(c) (i) Open Access

\begin{abstract}
Government of Uganda implemented the Local Government Development Program (LGDP) between 2000 and 2009 with support from multi-lateral and bi-lateral agencies. Unlike previous policies such as Structural Adjustment Programs (SAP's) and Liberalization Policies, LGDP was designed to address poverty following a participatory approach. The participatory approach involved improvement of service delivery where local communities identified, prioritized and implemented development projects. This approach ensured demand-driven service delivery with a performance assessment strategy through multi-level budget framework meetings organized to prioritize and evaluate the project outcomes. LGDP aligned with the overarching Poverty Eradication Action Plan policy by improving services delivery within the mandate of Local Governments. The services included health, education, street lighting, water supply, drainage, waste collection among others as provided for by the Local Governments Act. Funding was provided as Conditional and non-conditional grants released in each financial year for two grouped items of Local Development Grants (LDG) and Capacity Building Grants (CBG). This paper examines the fundamentals of participatory local development planning conceived as a people-centered approach in decisionmaking and how it contributed to development in Uganda. The paper also critiques the implications of LGDP upon aid withdrawal and its implications on locally generated mobilization of resources for sustainability.
\end{abstract}

\section{Keywords}

Local Governance, Participatory Development Planning, Urban Poverty, Decision Making 


\section{Introduction}

Poverty eradication has been and is still leading on the agenda for development in many developing countries (UN-Habitat, 2005; UN-Habitat, 2008). In Uganda eradicating poverty is a major objective of national, sub-national and local level planning with many actors involved (MoFPED, 2005; MoFPED, 2000). The actors include local governments, communities, NGO's and the private sector. Policies such as the Structural Adjustment Programs, Liberalization Policies, and Privatization policy have been implemented in the last three decades with the aim to transform Ugandan society out of poverty. But the envisaged outcomes of the programs have not been realistically achieved leading to persistent poverty in Uganda. In addition, poverty interventions in the past have reinforced the urban bias by focusing on rural areas leading to concentration of deprivation in urban areas. As observed in the participatory poverty assessment report (Bevan \& Sewaya, 1995; Ministry of Finance, 2001), rural and urban poverty can be distinguished with the latter predominantly manifesting in terms health outcomes, unemployment and or low pay compared to cost of living, poor drainage, poor housing and sanitation facilities. In Kampala poverty is still prevalent and a major challenge for development (Lwasa et al., 2009). But decentralization and improved local governance has been advanced as an alternative approach to addressing poverty. This approach has been widely implemented through Local Government Development Program (LGDP) in Uganda. LGDP was implemented between 2000 and 2009 to contribute towards transformation of decision making from a top-down to bottom up approach that enables communities to participate in identification, prioritization and implementation of development projects. This strategy has the basic ingredients of a people-centered approach in the revitalization of service delivery and driving of development in the country and city in particular (Lwasa \& Kadilo, 2010). The LGDP program was supported through an International Aid regime of multi-lateral arrangement between Uganda and development partners including developed countries and the World Bank. The paper examines how LGDP and the development planning process addressed the needs and priorities of urban communities.

Development planning in Kampala city is pursued through a process of budgeting, annual work plan development, 3-year rolling development plans and action plans. In these processes, focus is on allocation of resources mainly financial for increased productivity and improvement in socio-economic welfare. Despite the development programmes in Kampala City, poverty is still a challenge in urban management. Studies indicate that urban poverty is becoming worse than rural poverty (UBOS, 2002; Segendo, 2003; Ministry of Finance, 2000; Mitlin, D. \& Chitekwe, B., 2001). This study draws on a case study of four sites in Kampala focusing on plan formulation, prioritization and the implementation of development projects under the Local Government Development Program (LGDP) framework. Under LGDP framework community participation was an inherent component from the village to city-wide level. The paper examines the processes of assessing peoples' needs and the prioritization of these needs in resource allocation with emphasis on housing, employment and health services. The study focused on four objectives: 1 ) to identify the existing development plan formulation and implementation processes; 2) to assess the extent to which the plan formulation identified and prioritizes people's needs for improved service delivery; 3) to assess the effectiveness of development planning and implementation programs in addressing urban poverty; and 4) to examine the contribution of participatory and strategic approaches to urban governance. The paper examines the role of LGDP in poverty reduction and its contribution to transforming the urban communities.

\section{Analytical Framework}

Poverty has become increasingly concentrated in urban settlements attributed to the increasing urban population amidst inadequate resources to provide the basic services (Amis, 1995; Sengendo, 2003; UN-Habitat, 2008). The process of urbanization is contributing to the worsening conditions ushering in a "new" form and dimension of poverty that we conceptualize as "urbanized poverty". Urbanized poverty is analyzed in two ways; first the inadequacy of urban systems to provide services and opportunities to the population creating concentration pockets of deprivations in cities; and secondly elements of transformed rural poverty becoming concentrated in urban areas or otherwise the rurality character observed in urban areas of developing countries (UN-Habitat, 2005; Seto \& Reenberg, 2014). The concept of urbanized poverty is contested but evolving towards a consensus that urbanized poverty revolves around shared conditions of deprivation between individuals and households in urban neighborhoods (Brockerhoff, 2000; Hulme, 2003; MoFPED, 2007; UN-Habitat, 2008). This is because urban migrants as well as urbanites growing up in urban areas have no or limited marketable skills subsequently 
engaging in activities that are largely informal or considered rural-based. The UN-Habitat observes that the slum population is growing exponentially with average annual growth rate of $4.3 \%$ in cities of sub-Saharan Africa. (UN-Habitat, 2008) further notes that urbanization of poverty is related to systemic institutional failures that accentuates social exclusion and inequalities between the urban poor and the rich. This emerges from the inequitable resource allocation of urban investments by city management authorities (Lwasa \& Kadilo, 2010). Systemic institutional failures in urban service delivery are one of the key drivers of urbanized poverty (UN-Habitat, 2008). In urban service delivery, the most common approach is the project-based approach, which usually doesn't transcend pilot projects nor formulating strategies for scaling up. Because of pilot projects, communities are polarized between pockets of small urban communities with short to medium term improvements in living conditions while many remain comparatively poor due to lack of institutionalization of the good practices and lessons (UN-Habitat, 2005; Sengendo, 1997). This analytical framework of urbanization of poverty from systemic failures of institutions is utilized to explain opportunities for urban development pathways but also contest the challenges these pathways pose to inhibit improvement in quality life. Utilizing this framework, urbanized poverty is taken as a dynamic condition that involves adjustment among the urban population as expected quality of urban life is not achieved. The framework further considers the continued deprivation and resultant social relations that determine who to relate with, who to stay with, as important aspects of urban life (Enyedi, 2002; Hall, 1975). The resultant life experience of the urban populations is informalization of economic activities to create opportunities for the urban poor (Mukwaya et al., 2007). In the process of informalization, urban poor stay deprived for much longer periods than expected (MoFPED, 2005; Nyakaana et al., 2004). This has left many people in urban areas in a state of chronic poverty (KCC, 2008; Samura, 2008). This framework for urbanized poverty is utilized in this paper to understand the complex nature of the condition but also provide an entry point targeting of improvement by LGDP. Improved urban governance is critical in breaking the systemic institutional failures that underlie the persistence of urbanized poverty (Hulme, 2003). This illuminates local specific urban poverty that has remained chronic with localized impacts.

\section{Materials and Method}

The research was based on a case study design based on four administrative parishes. A multi-faceted methodological approach was utilized to elicit data on the process of prioritization, planning and implementation of projects. Interviews were conducted on a selected sample of households from the four sites to elicit data on beneficiary assessment of outcomes with an interview schedule. Focus Group Discussions were held in each study site to elicit data on community needs, priorities, resources available and opportunities for improvement in implementation of development plans. Additional interviews were also conducted with technocrats and project implementers. The research targeted the persons involved in delivery of services for the improvement of people's lives. These included planners, welfare officers, community development officer, parish development committee members, councilors and the council's sub-committee for planning. For a balanced assessment of the effectiveness of development planning, the research employed participatory techniques in identifying the needs of the people, resource allocation and utilization. Focus group discussions were conducted taking into consideration issues of gender, age, individual responsibility, local leaders to collect data from the community. The study sites comprised four administrative parishes of Mulago II, Kisasi, Bwaise III and Mpererwe within which development projects had been designed and implemented. Data from households was assessed for effectiveness of the implementation in meeting community needs. A total of 203 households were interviewed.

\section{LGDP, Development Planning and Poverty Reduction}

In Uganda various approaches exist for development planning such as budgeting, annual work plans, 3-year development plans and action plans (Ministry of Local Government, 2003). These approaches focus on allocation of resources mainly financial for increased productivity and improvement in socio-economic welfare. At the local level, development planning is the responsibility of local governments, which are mandated to prepare and implement plans for poverty reduction. Until 2000 when 3-year development plans under the Local government Development Program were launched, development planning was focused at sectors including housing, water, roads among others through the various departments (KCC, 1997). Decisions were made largely by the line ministries and or local government departments. Bottom-up approach to development planning has been rolled out in local governments through decentralization and reinforced by LGDP. The existing development planning 
cycle is governed by the Local Government Financial Year which runs from $1^{\text {st }}$ July to $30^{\text {th }}$ June. This implies that Local Governments prepare annual work plans within vestment estimates to be approved not later than the $15^{\text {th }}$ of June in the financial year. The significance of development planning in poverty eradication lies in the community identification of investment projects, community contribution to project investments and local decision-making concerning the allocation, prioritization and implementation of projects as elaborated in the guidelines for MoLG (2004). Budgeting for "investment plans" was predominantly the tool employed in development planning and implementation while community participation remains an integral part of the 3 year development plans (KCC, 2008). The responsibility for decisions concerning development falls on various stakeholders including communities, local leaders and the city-council sub-committee for planning. The motivation for this approach is three pronged; first the persistence of poverty and now urban concentrated poverty; second the critique on failure of foreign aid investment to get Africa out of poverty and third the emergence of new partnerships for pursuance of development in Africa in search for speedy development. Taken, as a people-centered approach to addressing poverty may not provide all the answers required for urban development, its potential benefits as exemplified by LGDP in Uganda can provide lessons for improved governance and development.

LGDP was also designed as a strategy for implementation of the devolution of powers in decision-making and financing framework for local authorities to enable inclusive participation in decision making processes. The LGDP was a government of Uganda programme that commenced in October 2000 and extended to 2009. It was designed for devolution of the development resources to the Local Governments (LGs). The total programme cost was US $\$ 88.9 \mathrm{~m}$ with US $\$ 52.5 \mathrm{~m}$ for direct investment in the local governments (KCC, 1999). Through the programme Government of Uganda provided technical and financial support to LGs including capacity building in governance. This was to enable LGs make investments efficiently through participatory resource allocation, planning and investment. This was to ensure that services provided by LGs are sustainable, delivered in a timely manner, considering value for money but also embed inclusive participation in decision-making. Under the programme, the LGs received the Local Development Grants (LDGs) and the Capacity Building Grant (CBG). Capacity to formulate 3 year rolling development plans was built based on a bottom-up approach. The phased LGDP targeted improvement in LGs performance of their statutory service obligations through effective, efficient planning, improved accountability and participatory monitoring and evaluation. An overview assessment of LGDP shows that 4745 projects were completed at a total cost of 29.4 billion Uganda shillings (exchange \$1 $=2200$ ) and the average cost of all investments was 6.2 million Uganda shillings (Kawempe Division Local Government, 2003; KCC and World Bank, 2000). Because of the investments, LGDP is considered to have contributed toward reduction of poverty as observed by Ministry of Local Government, 2004. LGDP also contributed to employment creation through private sector-led implementation of the investment projects, engendered service delivery and improving financial management by Local Governments. Local Governments started to improve communication with the public through display of information by local councils. This is assessed as having improved the public accountability and transparency especially in regard to expenditure, prioritization of resources by local governments. This preliminary assessment was conducted by the Ministry of Local Government monitoring and evaluation unit and this paper transcends this assessment to community-level and multi-actor assessment of the effectiveness (Friedman, 1987). The next section of the paper provides a community based assessment undertaken through this study.

\section{Results and Discussion}

This section of the paper examines the assessment of LGDP regime in addressing urban poverty from the community perspective.

\subsection{Health Needs and Delivery of Services}

The focus of this section is on public health services which involves ensuring prevention of diseases and the spread of such diseases as emanating from the nature and quality of environment in which people live (Kamulegeya, 2001). The delivery of public health services to the communities was planned and provided by the local government in the four study sites but lacking on some aspects. The community identified the Kampala City Council (KCC) health centers as existing and providing health services to the community. The interviews revealed that $96.1 \%$ of the respondents sought medical attention from KCC health centers. But respondents also sought medical treatment from multiple health facilities with $63.1 \%$ reporting seeking for attention in private 
clinics. The respondents noted that the health conditions are influenced by environmental characteristics that differed greatly between the study sites. During the FGDs, respondents noted that the environment has created breeding grounds for disease vectors and sanitation is inadequate since human waste disposal and management relies on pit-latrines. Under LGDP some public toilets were constructed but these were found inadequate because the need is greater in the congested neighborhoods. The public health needs were found to be high in terms of public toilets, drainage lining, solid waste management despite the LGDP investments. During the focus group discussions with the communities it was observed that the needs identified to address health outcomes included vector control (especially mosquitoes), drainage management, proper solid waste management and sustainable human waste disposal facilities for a healthy community.

In development planning under LGDP, prioritization of development projects was an inherent component in ensuring community development and poverty alleviation. The results showed a disjuncture between the community health needs and the health projects in the four sites. Although health needs ranked high on the priority list, the community was dissatisfied with the resource allocations. LGDP funding was mainly managed at municipal division level and the during the FGD's communities noted that the municipal division authorities implemented projects without full consultation as required by the participatory approach. The community FGD's raised suggestions to improve health services in the area and these included; construction of Community Health Centers, efficient handling and timely removal of garbage, construction and managing drainage systems and the further devolution of decision making to lower level governance structures. The findings show that development planning did cater for health but only on short-term basis. Planning for drainage lining, malaria control, public latrines and solid waste management as emergencies. Strategic planning has not been undertaken for sustainable maintenance of public health. The communities argued that previous efforts to control vectors yielded results, but the laxity today is partly responsible for the increased incidence of avoidable infections that are transmitted by the vectors. A major assessment by the communities was inadequacy in health needs assessment and project plan formulation.

\subsection{Employment Needs}

Employment opportunities are critical for the sustenance of the urban population and the economy at large but importantly for the urban poor. Employment has multi-dimensional outcomes with reduction of unemployment. It can improve the livelihood of the population as well as the revenue for the City Authority. Employment activities common in the four sites include masonry, vending, transportation and brick making for the majority of the population. According to the survey, $58.1 \%$ of the respondents were self employed while $29.6 \%$ are in private sector and 7.9\% employed by government. The survey further revealed that the major sources of household income included Trade/repair at 33\%, construction 16.3\%, petty trading/Hawking $18.7 \%$ and other forms $20.7 \%$. The results highlighted the need to create jobs in the areas employing majority in order to make the urban population more economically active. Employment at household level was showed that $68.7 \%$ of the households considered their employment as permanent, $12.8 \%$ seasonal, $15.3 \%$ part-time contract and $3.0 \%$ part-time. A further examination of the data also revealed that trade/repair, petty trade and other job descriptions predominate the permanent jobs as conceived by the households. But by nature of these predominating jobs, disguised unemployment was evident especially through petty trade and hawking. From the community FGD's it was raised that local transportation (using motor cycles) commonly known as Bodaboda, brick making, masonry and porter work are the major sources of income. The community observed that the types of jobs described only absorb few people leaving an average of $75 \%$ of the population that stays in the community throughout the day, unemployed. The statistic given was an estimation by the community from their experience and observations. A more refined statistic of $40 \%$ to be unemployed was reached by consensus after discussion that some people engage in part-time jobs. This was in consideration of the masonry and porter work in which jobs can be available for some weeks and not available for a period. Unemployment as estimated by community was high and explained by several factors as observed by the community representatives. The driving forces which converge for persistence of unemployment are several but LGDP offered "double-edged" opportunities for job creation through development projects which if implemented by communities would provide employment opportunities (Mukwaya et al., 2008). For example the construction industry would offer job opportunities for the population if it had been planned for and promoted in the LGDP. By transparently implementing investments that have components of construction such as roads, drainage systems, solid waste management, schools and health centers, it 
would translate into job creation. But the community noted that LGDP did not create employment opportunities because of the tendering and contractual process that favored private companies, which did not employ the community members where projects were implemented. Associated with the issue of informing the community about job creation and entrepreneurship is one seemingly outstanding issue of politicking in development planning and implementation. The community observed that development programs have been politicized so much that some community members and or leaders frustrate the projects due to their political inclinations. The community representatives in the FGD's noted that the politicization of development is not only a wrong act but a hindrance for overall development. Responsibility to direct development rests on the shoulders of the leaders but when the same leaders frustrate development, questions about social justice and governance arise.

Local communities noted lack of information on eligibility for their participation in tendering for projects despite the Local Government Act recognizing community contracting. Even when they are advertised in the print media, few people in the local community accessed the print media information. It was also pointed out that the tendering process was often flawed. For instance if one was to win the tender, favors had to be offered to some individuals who award the tenders. A further probing of the LGDP implementation revealed that people in the community were ignorant about the program since some of the projects were unfinished at the time of survey. The survey indicated that $53.7 \%$ of the respondents never heard of the 3 year development plan and those who heard about it did so through local council meetings. Similarly on LGDP, only $30 \%$ thought the community to have benefited while $24.1 \%$ were ignorant about LGDP. It was further revealed that the youth had not succeeded to get organized into groups to compete for public tenders. Therefore systemic impediments deprived the urban poor communities further through requirements such as registration fees, documentation of the organizations and requirements for tendering. The community suggested that capacity building involving information flow mechanisms for LGDP and other development projects needed to be stepped up. Thus the benefit of implementation of LGDP projects did not create the desired opportunities for job creation since the local people missed out on the contracts.

\subsection{Prioritization of Employment in Development Planning}

Although LGDP could help create the necessary jobs for the population, the investment projects were assessed as not adequately effective in job creation. LGDP focused on infrastructure for development, which was good because such infrastructure requires maintenance implying job creation even after the investment but with inadequate maintenance, jobs are only created during installation making it a short term measure. More construction related projects needed to be prioritized to provide employment opportunities for the urban poor. Thus investment in community infrastructure such as roads, drainage, water supply networks, and education had the potential to create employment opportunities. It is therefore important to note that assessment of employment needs of the community required to take into consideration the labor market potential for the majority of the population, which is semi-skilled to non-skilled and has flexibility in specialization.

The community felt that LGDP should have been used in a way to create jobs for the people in the locality. But the problems of deciding what the investment projects are and what is implemented was assessed as a critical weakness of the LGDP. Issues of rights emerged in which the community questioned who has the right over the projects being implemented. If it is the beneficiaries/owners, then the community had some rights but on contrary the authorities and contractors sometimes changed the decisions. For example in one of the study site there was construction of the drainage channel in the area which the contractors did but of low quality in terms of the depth and width of the channel. As a result conflicts emerged between contractor son one hand, and beneficiaries and the municipal leaders, technocrats on the other hand. Most times the shoddy work by contractors goes unchallenged and often overruled by the municipal leaders. In essence the community noted that decentralization had not enabled opportunities from development projects to locals in order to generate employment. The tendering process was not considerate to the local people because tenders are awarded to contractors who paid money to KCC as observed in the FGD's. Additionally, the transparency and accountability of the municipal leaders was questionable. For example because reported limited transparency, the community observed that $25 \%$ of taxes which was meant to be returned to lower administrative structures was no longer remitted.

Several suggestions were raised by the community as a way of improving development planning to increase employment. These included the following; LGDP and other future development projects need to prioritize job creation among the community members which would bring development and offer employment as well. The 
second was that other than markets, construction projects would offer as many jobs during and after construction. So if targeted by Kampala Capital City Authority (KCCA) it can improve on their revenue through taxes but also generate employment for the people especially the youth. Another suggestion for generating employment was community contracting in which communities would directly benefit from project implementation through employment in addition to the benefits of the project itself. This approach if promoted can be efficient, appropriate and alternative to the often expensive, top-down, contractor-driven community improvement.

\subsection{Development Plan Implementation Procedures}

From the analysis of the qualitative data, it emerged that development plan implementation was pursued using three tools. These included LGDP, Action plans and the Budget allocations. In all the cases, the 3 year development plans were the reference for plan operationalization. But the implementation procedures of these tools was assessed as not adequately effective in delivering the desired services to the communities. The survey revealed that $45.3 \%$ of the respondents had heard about the 3 year development plan while $53.7 \%$ had not. Only 9.9\% had heard about such plans through public meetings and 6.4\% through construction of projects. As regards the benefit from the investment projects, $30.5 \%$ noted that they had not benefited as a community, while $24.1 \%$ were ignorant about any LGDP projects. As regards participation and community mobilization, the survey revealed that $20.2 \%$ of the households had participated in the budget conferences during the parish meetings while $78.8 \%$ had not. Reasons for not participating included not being informed by $54.7 \%$ of the respondents and $6.4 \%$ had no interest. But $97 \%$ of the respondents noted willingness to participate in the budget conferences to give ideas. An evaluation of the efficiency of development planning was also done by the respondents in which $46.8 \%$ noted that it was poor, $36 \%$ assessed as fairly good and $10.3 \%$ as good. The main issues underlying this evaluation include corrupt officials at $43.8 \%$, ignorance at $20.2 \%$ and poor plan management at $17.7 \%$. LGDP was meant to benefit the community from projects which are generated by the communities themselves. There were numerous LGDP projects in the study sites, but development had not been achieved as desired. For example the LGDP would be a double-edged tool if communities were allowed to form organizations that can compete for the tenders with close monitoring by the municipal leaders and technocrats. This is because; it would take development to the community in terms of the infrastructure but at the same time offer employment to the population in the communities. According to the results of the key informant's interview, diversion of funds allocated to particular items is a common feature in the financial administration. This diversion was reported to delay of development projects and priorities of the communities. The key assessment suggestion was the prioritization of needs to be emphasized especially so if it reflects communities’ desire (KCC and BTC, 2008).

\subsection{Community Mobilization for Development}

LGPD ushered in a transformation of community participation in multi-sectoral projects which by integration attempted to address the multi-dimensions of poverty. A range of sectoral projects were implemented in the study stes. Analysis of the investment project expenditure revealed that prioritization in the different administrative parishes showed a wide coverage in terms of sectors. Investment projects implemented were in critical environmental infrastructure like sanitation, water, road construction, drainage works, community facilities, street lighting as well as social sector including educational facilities and health infrastructure (KCC, 2003). Through participation in the formulation and implementation of investment projects, LGDP attempted to address several dimensions of poverty in Kampala. Investment projects are integral because of the potential to create opportunities for employment, reduce community deprivation and enable communities to exercise their right to decide on problems and improving social and political development. It has been argued that projects would be owned by the people because full support by the community follows project design and implementation. Although there were some problems of proportionality of beneficiaries, disagreement between actors at various levels, LGDP ushered in a strategy for reducing poverty (Lwasa \& Nyakaana, 2005).

\section{Community Needs Assessment}

One of the ingredients of LGDP and poverty reduction was the mode of community needs assessment. Needs of a community are no longer assessed by technical staff from a line ministry or department of a local authority but by the community itself through meetings at different levels that filter through to the upper levels. Communities 
were given the power to identify, discuss and assess their community development needs. At a village level, community members discuss their problems, which are prioritized and forwarded to the parish level. From parish these are further ranked and forwarded to the sub county level. From this level the investment projects are integrated into the development plan and budgeted for. What proceeds is a series of budget conferences by the municipality and or city authority. By spreading investment projects across parishes, LGDP considered the spatial scale of poverty and addressed it from a locality. But significantly LGDP addressed the issue of participatory decision-making (Pedro, 2001). This has changed the approach to development and poverty reduction by listening and acting on the voices of the poor (Mbiba, 2000).

\section{Investment Project Prioritization}

In development planning under the decentralization framework, prioritization of development projects through the stages outlined earlier was an inherent component in ensuring community development and poverty alleviation. Prioritization involved ranking the problems and investment projects by importance and need. This was done at the different levels from community to local authority such as Kampala City Council. The study findings in Kampala indicated that there is a disjuncture between the assessed community needs and the projects at the municipal level. Priority projects for the parish and or village tended to differ from the priorities by the municipal authorities. This always created mistrust in the process and tension between the lower level planning committees and higher level planning committees. For example in two of the parishes investigated the community expressed dissatisfaction on health needs prioritization due to inadequacy in the prioritization of the actual needs of the community by the Municipal Council. In the Municipality of Kawempe the health center of Komamboga was considered inaccessible due to distance and costs by users from different parishes. Serving the whole municipal area the health center was reported as overwhelmed by the demand for health care. The development plan of 2003/04 prioritized expansion of the health center, yet the community felt that there is need to incorporate in the development plan health centers for the 22 parishes of the municipality. There was realization that population is growing and so the demand for services within proximity to the settlements. This view of the community was a foresight and captured the dynamic demographic and social conditions. Therefore the issue was not to have the health centers constructed at once but to having a strategic framework for health which would eventually offer better health services to the community. Such health centers can be constructed in phases over a time period in collaboration with communities. LGDP funding was mainly managed by the municipal division and did not reach parish level. The most significant complaint was that the community did not get a chance to implement their own projects. It was suggested that the Parish Development Committee (PDC) be given autonomy to control the development projects since they know the needs of the locals more and the local people's problems with the Municipal leaders as supervisors.

\section{Lessons from Foreign Aid Regimes}

From the foregoing discussion, some lessons can be drawn as experiences, success and failures of LGDP.

- Employment creation for communities; LGPD generated employment for local communities in which investment projects are implemented. Emphasis was on leveraging locally available labor which promoted redistribution of income amongst the beneficiaries. This acted as a doubled edged strategy that improved peoples employment but people also benefited form the outcomes of the projects.

- The preparation of development plans brought in practice hitherto only talked about and not tested. That is participatory planning which has been integrated to some degree into public policy and delivery of services paying off benefits in Uganda.

- Public accountability, transparency and quality control are additional lessons from this program. The decentralization policy had a requirement for public officers and political leaders to publically account for the resources at their disposal.

- LGDP and development planning also acted as an eye-opener for the community leaders and general public in Uganda that there is need for strategic planning rather than dealing with short term solutions to development problems.

- Mid-term range planning also provided a lesson on "thinking big” and "starting small”. This means projects such as road construction that require huge resources can be implemented in phases over the years through incremental implementation. 
- The need for continuous education that transcends sensitization or awareness would be a vital ingredient of poverty eradication in urban areas. People needed to know and understand what development means, how it is pursued, why it is pursued and how they can self mobilize to uplift their conditions of well being. Whether through formal education or otherwise, this issue will remain important on the poverty eradication agenda.

- The participation of communities in development initiatives as well as exercising rights in decision making propounds the people-centered approach to poverty reduction and greater development.

\section{Transcending Aid}

African countries have struggled to move out of aid driven development partly due to the conditions that come with such aid coupled with systemic institutional issues this is yet to be achieved. Scholars now acknowledge that foreign aid is not the solution to Africa's development challenges and the move out of the poverty trap. As argued by (Samura, 2008), 50 years of foreign aid has not lifted Africa out of poverty. He further points to governance as both the culprit and foe of Africa's development. Although debate on corruption has remained persistent, there are few cases of concerted effort to fight it remaining one of the critical tenets of governance. Cascading through all levels of decision making, poor governance characterized by corruption, lack of inclusiveness, lack of accountability, value for money and leakage of financial resources remain the stumbling blocks to poverty alleviation. The analysis and discussion in this paper shows that despite restructured urban governance systems, the processes of decision making are still bogged by inherent informal procedures on the basis of which one can argue that they explain the persistence of urban poverty. Mention and call for International Trade and partnerships, Foreign Direct Investments and indigenization of African development by leaders and scholars will remain on paper as long as the governance structures remain ridden by the poor governance elements.

\section{Conclusion}

Eradicating poverty is a very challenging and noble task due to the nature of poverty and its dynamism. LGDP implementation in Uganda and Kampala in particular provided some pointers to poverty reduction strategies that take into account the people's needs, aspirations, values and abilities. But participation of communities and process for consultations needs to be exploited more to enable informed decision making in regard to problems and needs of the community. The process of filtering community needs provides the basis for promotion and pursuance of people-centered approach to reduction of poverty. Thus governance and social justice as community participation in the development process need to be implemented to have effective delivery of services and reduction of poverty. In conclusion this study notes the significance of poverty reduction approaches that are people-centered both in plan formulation as well as implementation. There is a laxity in ensuring that needs are properly assessed and that projects do not only alleviate immediate problems but consider the future state of the community. It is also true that strategic planning can offer a window for fore-sighted planning within which short range planning activities can be conducted. This approach has not been fully utilized and therefore a need to refocusing on long range planning but without necessarily replacing the currently used approach of short range implementation of plans.

\section{References}

Amis, P. (1995). Making Sense of Urban Poverty. Environment and Urbanization, 7, 145-158. http://dx.doi.org/10.1177/095624789500700102

Bevan, P., \& Sewaya, A. (1995). Understanding Poverty in Uganda: Adding a Sociological Dimension. Oxford: CSAE.

Brockerhoff, M. P. (2000). An Urbanizing World. Population Bulletin, 55, 48.

Enyedi, G. (2002). The Social Sustainability of Large Cities. Vienna: ICSS.

Friedman, J. (1987). Planning in the Public Domain: From Knowledge to Action. Princeton, NJ: Princeton University Press.

Hall, P. (1975) “The City on the Highway” and “The City of the Permanent Underclass”. Cities of Tomorrow, 273-318, 361400.

Hulme, D. (2003). Conceptualizing Chronic Poverty. Washington: World Development Institute. http://dx.doi.org/10.1016/S0305-750X(02)00222-X

Kamulegeya, S. (2001). Health Provisioning and Social Networks in Kampala City: Implications for the Urban Poor. Unpublished Dissertation for MA, Makerere University. 
Kawempe Division Local Government (2003) Budget for Financial Year 2003-2004.

KCC (1997). Action Plan under the Local Government Development Plan. Kawempe Division: Kampala City Council.

KCC (1999). Revenue and Expenditure Budget 1999/2000. Kawempe Division: Kampala City Council.

KCC (2003). The Three-Year Development Plan 2003/04-200/06 (p. 236). Kampala: KCC.

KCC (2008). Kampala District 3 Year Development Plan. Kampala: KCC.

KCC and BTC (2008). Baseline Survey for the Kampala Integrated Environmental Management Project, Bwaise III (p. 81). Kampala: Kampala City Council \& Belgian Technical Cooperation.

KCC and World Bank (2000). Institutional Mapping of Services and Service Providers under the City Development Strategy. Kampala: KCC and World Bank.

Lwasa, S., \& Kadilo, G. (2010). Confronting the Urban Challenge in Sub Saharan Africa: Participatory Action Research. Institutional Capacity and Governance in Kampala. Commonwealth International Journal for Local Governance. Conference proceedings.

Lwasa, S., \& Nyakaana, J. B. (2005). Development Planning and Implementation Processes in Employment, Health Services and Housing Provision in Kawempe Division. Research Manuscript, Kampala: NURRU.

Lwasa, S., Tenywa, M., Majaliwa Mwanjalolo, G. J., Prain, G., \& Sengendo, H. (2009). Enhancing Adaptation of Poor Urban Dwellers to the Effects of Climate Variability and Change. 33. IOP Conference Series: Earth and Environmental Science, 6, Article ID: 332002.

Mbiba, B. (Ed.) (2000). Review of Urban and Peri-Urban Transformations and Livelihoods in East and Southern Africa. London: Urban and Peri-Uran Research Network (Peri-Net), South Bank University.

Ministry of Finance, Planning, and Economic Development (2000). Uganda Participatory Poverty Assessment Report: Learning from the Poor (p. 150). Kampala: Government of Uganda.

Ministry of Local Government (2003). Donor Programmes in Local Governments. http://www.molg.go.ug/projects.hei

Ministry of Local Government (2004). Second Local Government Development Programme (LGDP II) Operational Manual for Local Governments. Kampala: Ministry of Local Government.

Mitlin, D., \& Chitekwe, B. (2001). The Urban Poor under Threat and in Struggle: Options for Urban Development in Zimbabwe, 1995-2000. Environment and Urbanization, 13, 85-101.

MoFPED (2005). Uganda Poverty Status Report, 2005. Kampala: Government of Uganda.

MoFPED (2007). State of Uganda Population Report 2007. “Planned Urbanization for Uganda’s Growing Population” (p. 93). Kampala: Ministry of Finance, Planning \& Economic Development (Planning).

Mukwaya, P. I., Lwasa, S. et al. (2007). Urban Agriculture for Sustainable Livelihoods in Uganda (p. 93). State of Uganda’s Population 2007. MoFPED. Kampala: Ministry of Finance, Planning and Economic Development.

Mukwaya, P., Sengendo, H., \& Lwasa, S. (2008). The New Core Periphery Relations in Uganda: Institutional Responses in a Globalizing World. Inequality beyond Globalisation: Economic Changes and the Dynamics of Inequality Midterm Conference of the International Sociological Association's Research Committee Economy and Society, Neuchatel, 26-28 June 2008, ISA.

Nyakaana, J. B., Sengendo, H., \& Lwasa, S. (2004). Population, Urban Development and the Environment in Uganda: The Case of Kampala City and Its Environs. Kampala.

Pedro, M. (2001). Community Based Organization and Participatory Planning in South-East Mexico City. Environment and Urbanization, 13, 117-133.

Samura, S. (2008). The Pitfalls of Africa's Aid Addiction. http://news.bbc.co.uk/2/hi/africa/7740652.stm

Sengendo, H. (1997). Urbanization, Urban Governance and the Environment: Critical Conditions for Formulating of an Environmental Strategy for Kampala-Uganda. Mawazo Journal, 7, 18-31.

Seto, K. C., \& Reenberg, A. (2014). Rethinking Global Land Use in an Urban Era. Cambridge, MA: MIT Press. http://dx.doi.org/10.7551/mitpress/9780262026901.001.0001

UBOS (2002). Socioeconomic Conditions Based n the 1999/2000 Uganda National Household Survey. Entebbe: Uganda Bureau of Statistics.

UN-Habitat (2005). Responding to the Challenges of an Urbanizing World (p. 38). Nairobi: United Nations Human Settlements Programme.

UN-Habitat and ECA (2008). The State of African Cities: A Framework for Addressing Urban Challenges in Africa (p. 206). Nairobi: United Nations Human Settlement Programme. 